\title{
Structure in parasite component communities in wild rodents: predictability, stability, associations and interactions .... or pure randomness?
}

\author{
J. M. BEHNKE* \\ School of Biology, University of Nottingham, University Park, Nottingham NG2 7TR, UK \\ (Received 8 November 2007; revised 19 Fanuary 2008 and 22 Fanuary 2008; accepted 30 Fanuary 2008; first published online 27 March 2008)
}

\author{
S U M MAR Y
}

Experimental data establish that interactions exist between species of intestinal helminths during concurrent infections in rodents, the strongest effects being mediated through the host's immune responses. Detecting immune-mediated relationships in wild rodent populations has been fraught with problems and published data do not support a major role for interactions in structuring helminth communities. Helminths in wild rodents show predictable patterns of seasonal, host age-dependent and spatial variation in species richness and in abundance of core species. When these are controlled for, patterns of co-infection compatible with synergistic interactions can be demonstrated. At least one of these, the positive relationship between Heligmosomoides polygyrus and species richness of other helminths has been demonstrated in three totally independent data-sets. Collectively, they explain only a small percentage of the variance/deviance in abundance data and at this level are unlikely to play a major role in structuring helminth communities, although they may be important in the more heavily infected wood mice. Current worm burdens underestimate the possibility that earlier interactions through the immune system have taken place, and therefore interactions may have a greater role to play than is immediately evident from current worm burdens. Longitudinal studies are proposed to resolve this issue.

Key words: rodents, bank voles, wood mice, helminths, nematodes, interactions, associations, co-infections, immunity.

\section{INTRODUCTION}

Organisms in wild, natural ecosystems live in communities, where they interact with the environment around them and with other organisms (Tokeshi, 1999). Their abundance is subject to influences from extrinsic or abiotic factors, such as the precise location and nature of the habitat, the regional climate, and numbers fluctuate between years and seasons, depending on circumstances (Elton, 1927; Begon et al. 2005). They also interact with other living organisms, including members of their own species, in order to reproduce or for protection, and they compete for food and other resources, leading to density-dependent regulation of population sizes. Interactions occur also with members of other species, not the least in predator-prey relationships in food chains (Elton, 1927; Begon, Townsend and Harper, 2005).

Parasites likewise interact with the external environment: for example, their abundance may be dependent on climatic factors such as ambient temperature and humidity. Both are known to influence the development of free-living stages and affect the survival of transmission stages outside the host, as well as affecting the hosts themselves (Haukisalmi

\footnotetext{
* Corresponding author. Tel: +44(0)115 951 3208. Fax: +44(0)1159513251. E-mail: jerzy.behnke@nottingham. ac.uk
}

and Henttonen, 1990; Guernier, Hochberg and Guegan, 2004; Hudson et al. 2006). They also interact with other living organisms, foremost among which are the hosts within which they live, that provide their immediate environment. A unique facet of parasitism is that parasites are parcelled within hosts in infrapopulations and infracommunities, a concept originally developed by Bush and Holmes (1986) (See also later in this review and Esch et al. 1990). In some cases they may also be transmitted in packages, as for example when heavily infected intermediate hosts are consumed by predatory definitive hosts (Bush, Heard and Overstreet, 1993; Poulin, 2001). Each infrapopulation lives in a restricted environment delimited by the host's body. Within this space, each can affect the host in different ways, with consequences for the other co-infecting species (e.g. through the host immune response, pathology or nutrient limitation). Not surprisingly, therefore, in discrete populations of hosts, intrinsic factors such as host age, sex, diet, genetic status and social position, including lifehistory strategy, become varyingly important at influencing susceptibility to infection with parasitic and other invasive organisms (Barnard et al. 2002). Parasites within hosts interact with members of their own species (hence density-dependent regulation of infrapopulations is an important process limiting abundance and reproductive effort among parasites; Keymer, 1982) and finally they interact with other 
parasites exploiting the same host, and it is this, coinfection or polyparasitism, that constitutes the key theme of this issue.

Interactions between species within hosts can range from the mere coincidence of more than one species in the same host, through one species influencing the environment within that host in a way that benefits or impairs the survival of the second species, to species actually interacting directly. The latter may arise physically because parasites are crowded into a space-restricted site, through competition for resources, or via chemical mediators (e.g. 'allomone-like' substances, metabolic by-products Roberts, 2000; Pedersen and Fenton, 2006). Added complexity in co-infections is generated by correlated exposure, by parasite longevity, by differences in the genetic constitution of individual hosts, and by broader effects on the hosts' immune system through commitment to a particular response phenotype (e.g. Th1 versus Th2). The latter feature in particular is a fertile field of current interest (Graham, 2002; other contributors to this special issue). There can be profound consequences from such co-infections, with one species enhancing the susceptibility of the host to other life-threatening infections (Booth and Bundy, 1992; Nacher, 2002; Druilhe, Tall and Sokhna, 2005; Pedersen and Fenton, 2006), and concern has been expressed about how little we actually know about the cumulative effect of coinfections on the health of the host (Buck, Anderson and MacRae, 1978b; Keusch and Migasena, 1982; Ezeamama et al. 2005). This paper will focus almost entirely, but not exclusively, on co-infections of helminths in laboratory and in wild rodents. After reviewing some of the most persuasive evidence for the existence of interactions between species, based on laboratory studies, I hope to demonstrate that relationships between species compatible with an underlying interaction can be detected in field data, but that they need to be interpreted with due caution. In order to detect them a sound, comprehensive knowledge of the structure, predictability and composition of helminth communities is an essential pre-requirement. I make no apology for the selective use of the literature, since several comprehensive reviews of the subject have been published already, to which the reader is referred (Dobson, 1985; Christensen et al. 1987 ; Petney and Andrews, 1998; Behnke et al. 2000), and for focusing particularly on our own work: such was my remit.

TYPES OF INTERACTIONS AND SOURCES OF ERROR

Interactions between species can be synergistic, that is positive, one species benefiting another. A good example of such an interaction among free-living animals can be found in the relationship between the large blue butterfly (Maculinea arion) and rabbits
(Oryctolagus cuniculus). However, this is not a simple relationship. High rabbit density does not directly create large butterfly populations or vice versa, but rather rabbits keep the grass low, allowing ants and their colonies to proliferate, providing a secure environment for the larvae of the large blue butterfly (Warren and Wigglesworth, 2007). This first example, therefore provides us with due warning that the interpretation of analyses of interactions between organisms needs to be tackled with extreme caution, because of the scope for jumping to oversimplistic and erroneous conclusions.

Some associations may benefit both species, as in the case of the well known relationships between ants and aphids (Stadler and Dixon, 2005). Synergistic relationships can range from the loose commensal, with little specificity, as in the case of bees pollinating a wide range of plants (Biesmeijer et al. 2006), to the absolutely specific and obligatory as in the case Darwin's hawkmoth (Xanthopan morganii) and the orchid Angraecum sesquipedale (Nilsson, 1998).

As already intimated, analyses of co-ocurrences of animals, with the intention of discovering underlying interactions between species, are fraught with problems, not least statistical problems and the risk of false conclusions through failure to control for environmental factors that concentrate animals together in some subsets of the population (Haukisalmi and Henttonen, 1998; Howard, Donnelly and Chan, 2001 ; Behnke et al. 2005). Indeed, population structure often appears to generate the spurious appearance of interactions through genetic, spatial, age-related and ecological effects, and I would like to illustrate this with a very simple example.

In a survey of animals living on a golf course, frogs and damselflies occur in certain sectors of the total area surveyed but not in others. Moreover, sectors with large numbers of frogs also have many damselflies, whilst those with few frogs have low numbers of damselflies. It may be tempting to interpret this as reflecting interactions between the species with high abundance of frogs generating a high abundance of damselflies or vice versa. However, the true explanation is much simpler. In this case the golf course has many temporary and larger permanent ponds, and some are richer in biodiversity than others, supporting larger populations of both species. So, indirect effects can stem from some quality of the environment, which benefits both species (Wootton, 1994) and encourages cooccurrence, rather than because of any specific interactions between frogs and damselflies. This self-evident truth of free-living community ecology underlines the importance of distinguishing between co-occurrence of species based on convergence of common ecological processes that bring species together or separate them, and co-occurrence based on direct interactions between species (Howard et al. 2001, 2002). It can be easily obscured in parasitology, 
where interactions have to be identified from cooccurrence in the host, and co-occurrence of the free-living and infective stages as well.

Interactions between species can also be antagonistic, often referred to as negative interactions, for example, exploitative or food chain relationships when the abundance of one species lowers that of the other. They can be competitive, based on exploitation of the same resource, when both species may suffer if the resource is limited (Begon et al. 2005). They can also be indirect, for example when a common pathogen lowers the fitness of both species in situations where they co-occur. So on damp pasture grazed by sheep, the amphibious snail Lymnea truncatula may occur, and if it is infected with Fasciola hepatica this is likely to impact on abundance/fitness of both hosts in the cycle.

Co-occurrence of parasites, or polyparasitism, is well known in the medical (Buck et al. 1978 $a, b$; Ashford, 1991), veterinary (Diez-Baňos, Cabaret and Diez-Baňos, 1992) and zoological literature (Haukisalmi and Henttonen, 1993). The majority of animals in naturally existing wild communities (Lotz and Font, 1994; Nilssen, Haugerud and Folstad, 1998; Lello et al. 2004), and humans living under conditions of exposure, carry several species of parasites concurrently (Buck et al. 1978 a ; Keusch and Migasena, 1982; Kvalsvig, 1988; Ashford, Craig and Oppenheimer, 1992; Booth et al. 1998; Bottomley, Ishan and Basanez, 2005). Some of these are more often encountered together than expected by chance, and among co-occurring species there may be quantitative associations, such that heavy infections with one species seemingly predispose to heavy infections with the other. To give one well known example among human parasites, Ascaris lumbricoides and Trichuris trichiura often co-occur in infected individuals. Many different studies have highlighted their co-occurrence in human populations living in developing countries (Holland et al. 1989; Booth and Bundy, 1992; Howard et al. 2002). Tchuem Tchuenté et al. (2003) found a highly significant positive relationship between the intensity of both species among those children that were passing eggs of both species (after exclusion of all double and single negatives). However, the data were generated through a survey of 5 schools, in which there were both boys and girls in 12 age classes. Abundance differed between schools and age classes, so these had to be taken into account to avoid erroneous conclusions. This was achieved by fitting minimum sufficient statistical models in generalized linear models to the data and examining the relationship between the residuals. Having controlled for differences between schools and age classes, the relationship was now weaker, indicating that some degree of correlated exposure was involved. Nevertheless the relationship survived the analysis and was still significant.
Table 1. Helminth parasites of rodents that have been used in studies of interactions between intestine dwelling species

\begin{tabular}{ll}
\hline \hline Nematodes & Trichinella spiralis \\
& Trichuris muris \\
& Nippostrongylus brasiliensis \\
& Heligmosomoides bakeri* \\
& Strongyloides ratti \\
& Hymenolepis diminuta \\
Cestodes & Hymenolepis citelli \\
& Rodentolepis microstoma** \\
Acanthocephala & Moniliformis moniliformis*** \\
\hline \hline
\end{tabular}

* Previously known as H. polygyrus and Nematospiroides dubuis.

** Previously known as Hymenolepis microstoma. *** Previously known as M. dubius.

But even when all these relevant controls have been considered, does co-occurrence of species mean that the one species facilitates or antagonises the other? Not necessarily. Both A. lumbricoides and $T$. trichiura have robust, well-protected eggs, thus individuals in the data subsets who showed poor hygiene would be likely to be exposed to both. Coabundance is therefore not necessarily attributable only to interactions with one species predisposing to infection with the other, but may more likely reflect the coincidence of similar transmission strategies. In the majority of co-infection studies on these two species correlated exposure has not been taken into account. The challenge now is to quantify human behaviour that enhances transmission in these children, as for example by measurement of ingestion of silica (Bundy, 1988) and to control for that. My prediction is that the quantitative relationship between the intensity of infection with $A$. lumbricoides and $T$. trichiura will largely disappear when this additional control is brought into the analysis.

\section{LABORATORY MODELS OF POLYPARASITISM}

How can we explore the underlying processes, causes and effects, in more detail? My initial strategy was to explore interactions in laboratory models under the precisely controlled conditions of laboratory experimentation first, and then to test the predictions of laboratory-generated data in the field. A wide range of useful and relevant model systems is available (Table 1) for such work and these have been used extensively, although the work was largely conducted in the 1970s and is mostly forgotten.

The classic work of John Holmes (1961, $1962 a, b)$ is seldom cited these days. Hymenolepis diminuta and Moniliformis moniliformis both usually occupy the anterior region of the gut of rats but Holmes found that when rats were co-infected, $M$. moniliformis was able to hold its own, staying in the preferred site, while $H$. diminuta was 'pushed' back to 
non-optimal distal regions of the small intestine. But this is not the end of the story. There are two further twists, because $H$. diminuta is far longer lived than M. moniliformis, and as the latter dies of senility, the former moves back up into its preferred site. Equally of interest, Holmes (1962b) failed to find the same relationship between these species in a different host, the hamster. It is also relevant that $H$. diminuta is a species that is particularly sensitive to crowding effects (density-dependent regulation), its size and fecundity being severely affected even when just two worms, rather than a single worm, are present (Read, 1951; Roberts, 2000). These papers by Holmes are widely regarded as the start of the field of quantitative helminth community ecology (Esch et al. 1990; Janovy, 2002).

Holmes (1973) hypothesised that where competitive interactions occur in ecological time, the interacting species that is the superior competitor would bring about the extinction of the weaker competitor, or force it to survive as an opportunistic organism, exploiting hosts only in situations where the superior competitor was absent. Over evolutionary time, we may expect some stabilisation by specialization to eliminate the competition, leading to selective segregation.

Gerry Schad (1963) made a seminal contribution to this concept. Schad worked on the pinworms of Greek tortoises, which were parasitized by 8 species of oxyuroid nematodes of the genus Tachygonetria. Hosts can be very heavily parasitized, and the 8 species have become specialists to avoid competition. Thus T. uncinata and T. numidica show virtually identical longitudinal distribution in the colon of tortoises, but it turns out that the former is a mucosal species, whereas the latter lives in the lumen. When Schad looked at the other species, it was evident that half were mucosal and half lumen dwellers, and he was able to match up approximately similar longitudinal distributions with this mucosal/ luminal separation. Where both longitudinal and radial distributions were similar (e.g. T. robusta and $T$. stylosa), their feeding strategies differed. Thus $T$. robusta is an indiscriminate feeder, whereas $T$. stylosa feeds on fine particles such as bacteria. As a consequence of such adaptations over time site, resource and temporal segregation have evolved to minimise competition and niche overlap.

However, the situation may be even more complex and controversy has continued to this day. Some workers have argued that in particular hosts there may be many vacant niches and that the driving forces for niche segregation and speciation are reinforcement of reproductive barriers and maximum utilisation of food resources (Price, 1980; Rohde, 1991 and see Esch (1990) and Janovy (2002) for reviews of the conflicting debate in this field). There is also the possibility that the assemblage of Tachygonetria spp. resident in Schad's tortoises was

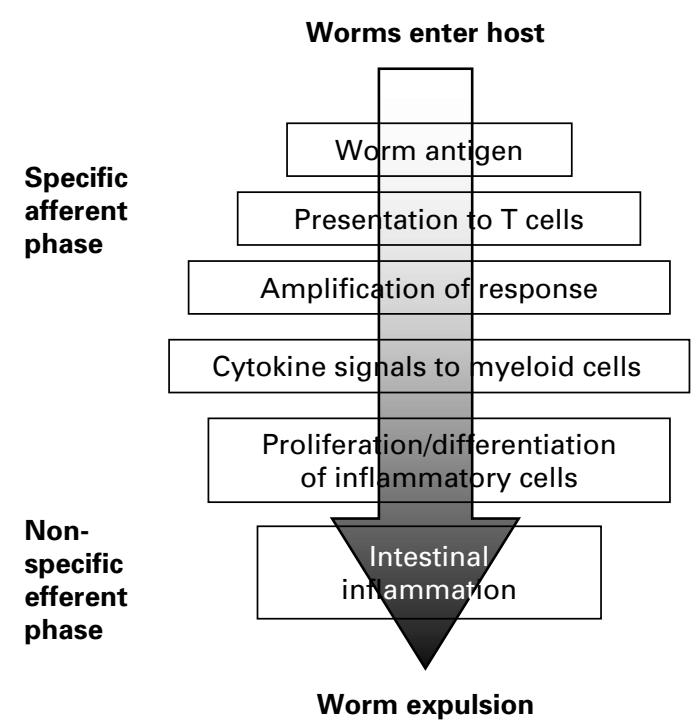

Fig. 1. Schematic diagram of the major stages of an adaptive immune response to parasitic infection in vertebrates.

acquired by host capture from other reptiles, in which they had evolved to exploit slightly different host resources.

THE IMMUNE RESPONSE AS AN

ENVIRONMENTAL STRESSOR

Parasitism, of course, has unique ecological features in so far as free living organisms do not have to face the threat of the environment conspiring specifically to destroy them. As with all other ecological problems, parasites have to adapt or die and over evolutionary time hosts refine their mechanisms of defence, whilst parasites develop new counter measures (Behnke, Barnard and Wakelin, 1992; Maizels et al. 2004) and this generates the Arms Race, also known as the gene-for-gene or Red Queen hypotheses (Dawkins and Krebs, 1979; Anderson and May, 1982; Behnke and Barnard, 1990).

The details of the immune system are given elsewhere (Murphy, Travers and Walport, 2008). However, the features of relevance to what follows are summarised in Fig. 1. Initially the adaptive immune response of vertebrates involves a covert afferent phase during which recognition of foreign invaders takes place and, eventually, this is translated into an effector phase during which the actual defences are unleashed. The latter can be pathogenic for the host and come at a cost (Castro, Olson and Baker, 1967; Mercer et al. 2000), but it is during this effector phase that worms can be expelled from the host. We have been arguing for some time about whether a magic bullet exists within the complex array of effectors (Pemberton et al. 2004; Anthony et al. 2006; Artis, 2006; Artis et al. 2004), but the fact is that once unleashed some components of the response to intestinal helminths, whether effective 
Table 2. Antagonistic interactions between intestinal nematodes. In these examples one species induces an immune response in the host, and a second co-infecting species is severely impaired, and even expelled by the non-specific consequences of the effector mechanisms induced

\begin{tabular}{lll}
\hline \hline Inducing parasite & Affected parasite & Reference \\
\hline Trichinella spiralis & Trichuris muris & Bruce and Wakelin (1977) \\
T. spiralis & Hymenolepis diminuta & Christie (1979), \\
& Silver et al. (1980) \\
T. spiralis & Rodentolepis microstoma & Howard et al. (1978) \\
$\begin{array}{l}\text { Nippostrongylus } \\
\text { brasiliensis }\end{array}$ & T. spiralis & Kennedy (1980) \\
T. spiralis & N. brasiliensis & Kennedy (1980) \\
\hline \hline
\end{tabular}

For comprehensive list of other combinations see Christensen et al. (1987).

against the triggering species or not, can be detrimental to other species.

Five broad categories of such interactions arising from this immune interaction can be envisaged. Species such as Trichinella spiralis generate an intestinal immune response during which gut function is severely affected and, as the immune response intensifies, so worm numbers decline. Concurrently marked changes in a range of cellular and soluble mediators can be detected, reflected for example in mastocytosis on the one hand (mast cell numbers increase and degranulate, releasing their highly toxic compounds) and in changes in the expression of receptors of signals from cytokines, including adhesion molecules, on the other hand (Else and Finkelman, 1999; Gause, Urban and Stadecker, 2003; Nair, Guild and Artis, 2006).

If a lumen dweller such as $H$. diminuta is present during this expulsion phase, it is severely affected (Behnke, Bland and Wakelin, 1977; Christie, Wakelin and Wilson, 1979; Silver, Dick and Welch, 1980). Fig. 2 shows that in control mice $90 \%$ of worms established and survived, and grew to about 1-2 $\mathrm{mg}$ in weight by day 8 , whilst in mice responding to $T$. spiralis, survival was just $7 \cdot 5 \%$ and the biomass was only $0 \cdot 1 \mathrm{mg}$. However, when the immune response was suppressed, in this case by treatment with the wide-spectrum steroid immunosuppressant cortisone, $H$. diminuta could survive and grow alongside $T$. spiralis without any evident detrimental consequences. Table 2 summarises many similar examples, all work conducted in the 1970 s and early 1980s. As with all biological processes, however, there are some exceptions. Hookworms were able to survive the acute phase of the inflammatory response to $T$. spiralis in concurrently infected hamsters without any loss (Behnke, Rose and Little, 1994), a reflection of their remarkable resilience in the face of the host's immune response (Loukas and Prociv, 2001).

In some cases there may be genuine cross immunity between species, a topic of immense importance in the race to develop vaccines against

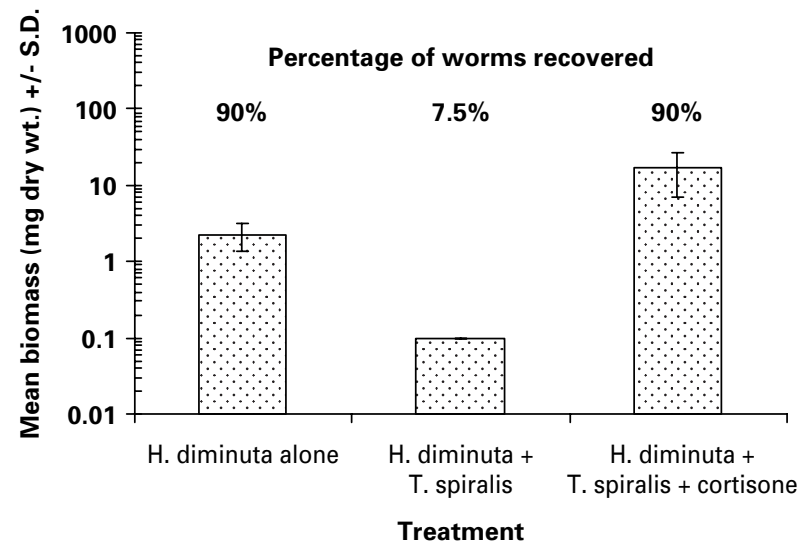

Fig. 2. Loss of Hymenolepis diminuta from mice concurrently infected with Trichinella spiralis at the height of the response to the latter species. The figure shows the percentage survival of worms and the mean dry biomass ( \pm standard deviation), following administration of 5 cysticercoids to each animal, eight days before autopsy. The mice were given 450 larvae of $T$. spiralis one day before infection with $H$. diminuta. Note that the error bars cannot be seen in the middle column because they are too small to be illustrated on the scale used. For further details of methods used including details of treatment with cortisone see Behnke et al. 1977.

gastro-intestinal (GI) nematodes of ruminants, where cross-immunity would be a practical asset, protecting not only against the inducing species, but against other co-infecting nematodes. There have been disappointments on this front (Adams, Anderson and Windon, 1989), but one example of the successful demonstration of cross immunity between species is in the interaction between T. spiralis and Strongyloides ratti. Moqbel and Wakelin (1979) showed that even when rats were challenged with $S$. ratti $1 \cdot 5$ months after $T$. spiralis infection, establishment and survival of $S$. ratti were severely affected, long after the inflammation stimulated by the initial $T$. spiralis infection would have died down (See also Nawa et al. 1982; Mimori et al. 1983). 
Table 3. Synergistic interactions between intestinal helminths. In these examples the first species is Heligmosomoides bakeri, and this depresses the immune response to other co-infecting species, prolonging their survival in the host

\begin{tabular}{|c|c|c|}
\hline $\begin{array}{l}\text { Inducing } \\
\text { parasite }\end{array}$ & Affected parasite & Reference \\
\hline H. bakeri & Rodentolepis microstoma & Courtney and Forrester (1973) \\
\hline H. bakeri & Nippostrongylus brasiliensis & Jenkins (1975), Bruna and Xenia (1976) \\
\hline H. bakeri & Trichuris muris & $\begin{array}{l}\text { Jenkins and Behnke (1977), } \\
\text { Behnke and Ali (1984) }\end{array}$ \\
\hline H. bakeri & Trichinella spiralis & Behnke et al. (1978) \\
\hline H. bakeri & Hymenolepis diminuta & Hopkins (1980) \\
\hline H. bakeri & Hymenolepis citelli & Alghali et al. (1985) \\
\hline
\end{tabular}



Fig. 3. Extended survival of $T$. spiralis in mice concurrently infected with H. bakeri. The figure shows the mean number of T. spiralis recovered and the accompanying mast cell response. Mice were given 300 larvae of T. spiralis on day 0 , the concurrently infected group having been infected with 300 larvae of $H$. bakeri 8 days earlier, and were killed in groups on the days shown. A small piece of intestinal tissue was taken for mast cell counts and mast cell counts are expressed in terms of the number of mast cells in 20 villus crypt units (VCU) per mouse. The figure shows that mice harbouring $T$. spiralis alone mounted an intense mast cell response that peaked on day 12 after infection (open squares and bold line), by which time most of the T. spiralis had been expelled (speckled columns). In contrast in mice that were infected with $H$. bakeri 8 days earlier and then challenged with $T$. spiralis, the mast cell response was severely depressed (filled in squares and thin line) and expulsion of $T$. spiralis was considerably slower with little evidence of loss on day 12 (filled in columns). A gradual decline of $T$. spiralis worm burdens was evident on days 15 and 18 , but infections are known to persist for over 6 weeks in this combination (Behnke et al. 1978). For further details of this experiment see Dehlawi et al. (1987).

Some species are able to depress the immune response to benefit their own survival. A classic example of this is Heligmosomoides bakeri. When mice are infected with $H$. bakeri before $T$. spiralis, the latter survives much longer (Fig. 3). Expulsion is slowed down and the mast cell response is severely depressed (Behnke, Wakelin and Wilson, 1978; Dehlawi, Wakelin and Behnke, 1987). Much the same is seen when other parasites replace $T$. spiralis as the co-infecting species and Table 3 summarises some of the studies that have shown this to be the case. Although the mechanism of this immunodepression is not fully understood it is likely to be based on immunomodulatory factors released by the worms that specifically depress components of the host response such as mastocytosis (Behnke et al. 1992; Wilson et al. 2005; Rzepecka et al. 2006).

Other parasites alter the balance of the host's capacity to mount Th1 and Th2 responses or affect regulatory $\mathrm{T}$ cells (Wilson et al. 2005). By initiating a Th2-driven response in the host, helminths may make the host more susceptible to concurrent infections that are better controlled by Th1 responses and vice-versa (Graham et al. 2007; Graham, 2008). In the latter context it is, of course, equally possible that, by initiating a Th2 response in the host, one species may make the host environment more conducive to Th2 bias against a second species, also best 
controlled through this arm of the response, and vice versa. This represents antagonism between species.

So to summarise, interactions between parasites mediated through the immune system fall into five broad classes, three of which are antagonistic (nonspecific interactive expulsion, cross immunity and induction of a host protective Th1/Th2 bias against the second species) and two synergistic (non-specific immunomodulation and induction of Th1/Th2 balance inappropriate for host-protective immunity against the second species).

IS THERE ANY EVIDENCE THAT SUCH

INTERACTIONS EXIST IN THE FIELD?

\section{Sources of data}

It is the second group, the synergistic interactions, that has been a particular interest of mine. Building on the laboratory experimental work with colleagues and collaborators I have looked for evidence that the naturally occurring relatives of $H$. bakeri make wild rodents more susceptible to infection or enhance infections with other species of parasites. A particular focus of my field work therefore has been to determine whether synergistic interactions can be detected when one of the infecting species is a close relative of $H$. bakeri. Interactions as such are unlikely to be substantiated through correlations between prevalence or abundance of species, because correlational tests can never unravel cause and effect. However, if they exist we can make relevant predictions about the nature of these relationships. In this case we might predict that in the presence of heligmosomatids, wild rodents should show higher prevalence of other species of parasites compared with rodents not infected with heligmosomatids, and we might expect there to be a quantitative positive relationship in abundance of the two species among animals that carry both. If this turns out to be the case in several nonoverlapping, independently collected data sets, based on hosts from diverse habitats and different combinations of other quantified factors, it would be difficult to dismiss as mere co-incidence based on random events.

To examine this, together with colleagues elsewhere, I have been exploring a number of such datasets. For $H$. polygyrus, the naturally occurring heligmosomatid of woodmice (Apodemus sylvaticus) we have three data-sets, two from the UK and one very recent data set acquired through collaboration with Catarina Eira in Portugal, Jordi Torres in Spain and their colleagues (Eira et al. 2006). We have long-term datasets on almost fully censused parasite communities of bank voles (Myodes glareolus) from Poland (Behnke et al. 2001) and extensive data on spiny mice from Egypt (Behnke et al. 2004).
Confounding factors affecting variation in parasite burdens

Before we can set about looking meaningfully for associations between helminth species that reflect possible underlying interactions, we have to understand the structure, composition, predictability and the stability/instability of the communities of which they are members. We must therefore examine some of the complexities that need to be tackled if we are to make sense of the data.

For all hosts, the full list of parasites described from those hosts is known as the total helminth fauna of that species, but no study actually encounters the full list, because hosts are usually sampled locally in a region within the range of the host, and regional helminth fauna is usually only a subset of the total (Poulin, 1998). Moreover, few investigators actually conduct a comprehensive autopsy searching within each conceivable location of the host, often specializing, for example, in just intestinal parasites. Within each region are parasite component communities of that host, comprising metapopulations of individual parasite species that circulate among the host metapopulation in a definable ecosystem, perhaps discreet woods, fields or other types of habitats. At the lowest level we have infracommunities which comprise infrapopulations of all the species encountered within an individual animal, and which are therefore in closest contact with one another (Poulin, 1997, 2004). It is interactions between infrapopulations within infracommunities, repeatedly observed in different component communities, that we seek to identify, but first I will outline some general patterns of parasite infra- and component-community structure in rodents, using data on helminths in bank voles.

\section{Helminth communities in bank voles in Poland}

In the NE of Poland we have been studying helminth communities in bank voles in 3 woodlands. Each has been surveyed in 1999, 2002 and 2006 always in late summer between the end of August and the first weeks of September. One of these sites has been followed for 10 years since 1998. The 3 sites lie almost on an exact straight line NE to SW across the region as described by Behnke et al. (2001). They are separated by water barriers, including lakes, rivers and canals, and also by open arable land. The data from 2006 have not yet been completely analysed so what follows is mostly based on the first two expeditions to the region (1999 and 2002) and this comprises three sites, two years, but only one season, autumn. All these animals have been fully censused for helminths, haemoparasites, ectoparasites and 2 species of intestinal protozoa. Their morphometrics are recorded in meticulous detail and we have tissue samples from every animal for eventual genetic analysis. 

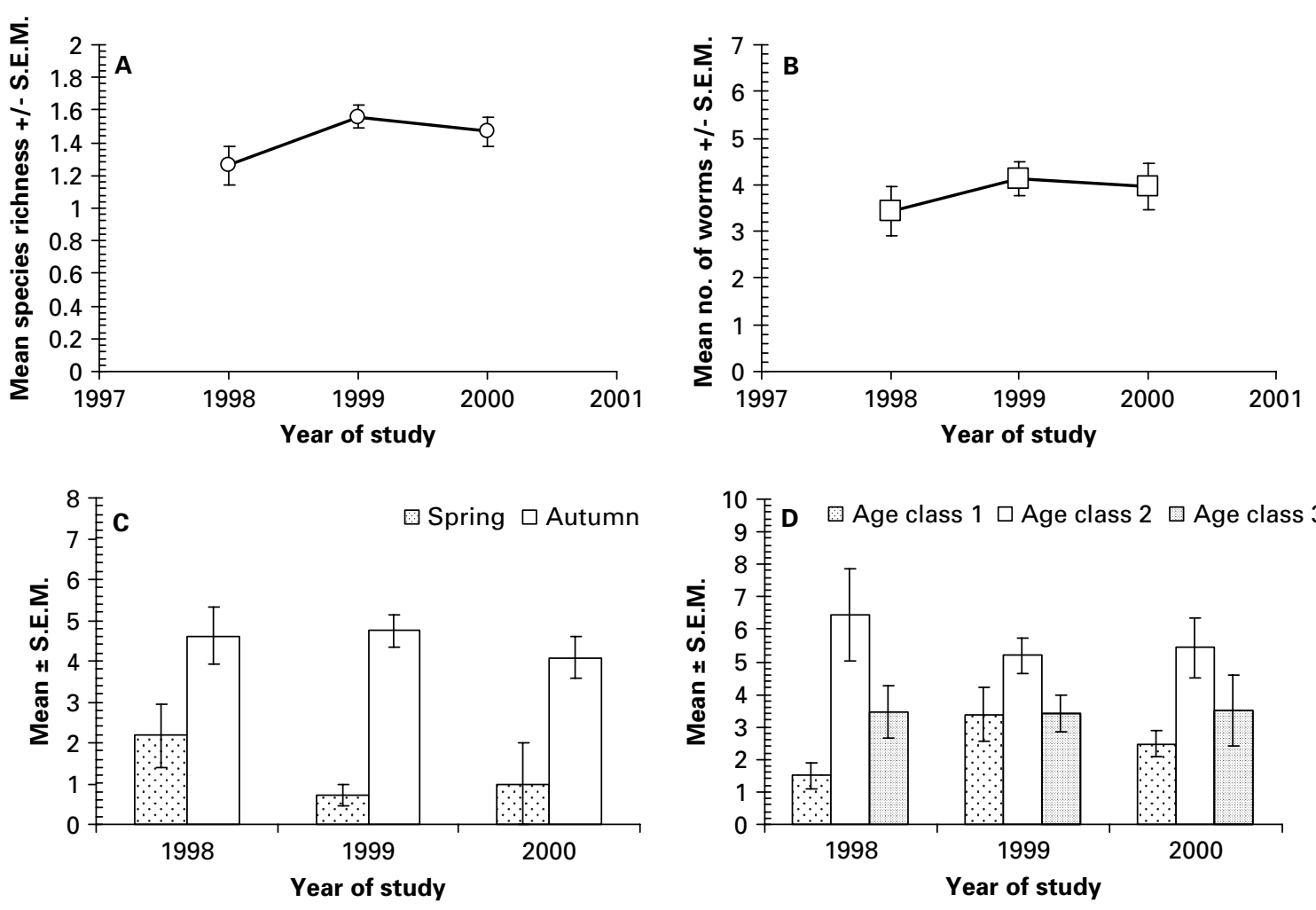

Fig. 4. Medium term stability in mean helminth species richness (A) and mean worm burden with Heligmosomum mixtum (B) in bank voles at Urwitalt, despite predictable patterns of season (C) and host age-dependent (D) variation in H. mixtum burdens. For full details of statistical analysis see Bajer et al. (2005).

We initially collected raw data on the abundance of each species in each host, and calculated standard derived variables such as species richness and indices of diversity. These helminth communities differ remarkably between the three sites in some respects but not in others, depending on which parameters are examined. So for example mean species richness varied from approximately 1 to 2 species per animal, but relative ranking of sites changed between the first two surveys. Species richness and Brillouins' index of diversity were both highest at Pilchy in 1999, but then at Urwitalt in 2002. So for derived measures, the relative ranking of sites changed, but the actual range of mean values was narrow indicating fairly modest change overall (Behnke et al. unpublished).

In contrast, when we examined individual species, the relative ranking across sites remained the same. Thus Heligmosomum mixtum always showed highest abundance at Urwitałt, intermediate at Talty and was never seen at Pilchy. In contrast, Heligmosomoides glareoli was most abundant at Pilchy, abundance was lower at the other two sites, but even within that range it was more abundant at Talty than Urwitałt. Objective measures of the relative importance of this effect of site in comparison to other quantified factors such as year of study, age and sex of host, can be derived by calculating the percentage of deviance explained by each factor for each species in the study, after fitting minimum sufficient models that most parsimoniously explain the variation (deviance for GLMs) in data. When we fit GLM models in R, the most important factor explaining deviance is always site. By comparison the difference between years explains far less deviance, as does the intrinsic factor age (Behnke et al. unpubished).

Focusing on Urwitalt in more detail, it can be seen that mean species richness in the period 1998 to 2000 did not change significantly, nor did the mean abundance of $H$. mixtum, and that despite a strong seasonal difference between spring and autumn and highly significant effects of age in each year of this study. The abundance of $H$. mixtum always peaked in the young adults and dropped in the older animals (Fig. 4; Bajer et al. 2005).

Our studies on helminths in bank voles in NE Poland continue and the recent expedition in 2006 will add eventually another 268 individuals to the database. At this stage we have not yet looked for interactions between helminths in these datasets preferring to document comprehensively and to evaluate the relative role of the intrinsic and extrinsic factors that we have measured. With this knowledge, we will eventually be able to fit models that are robust and take all confounding factors into account. Not the least, we will be able to determine whether any detected co-occurrences of species form repeatable relationships that occur in different years of our longterm study and in each of our three study sites. 

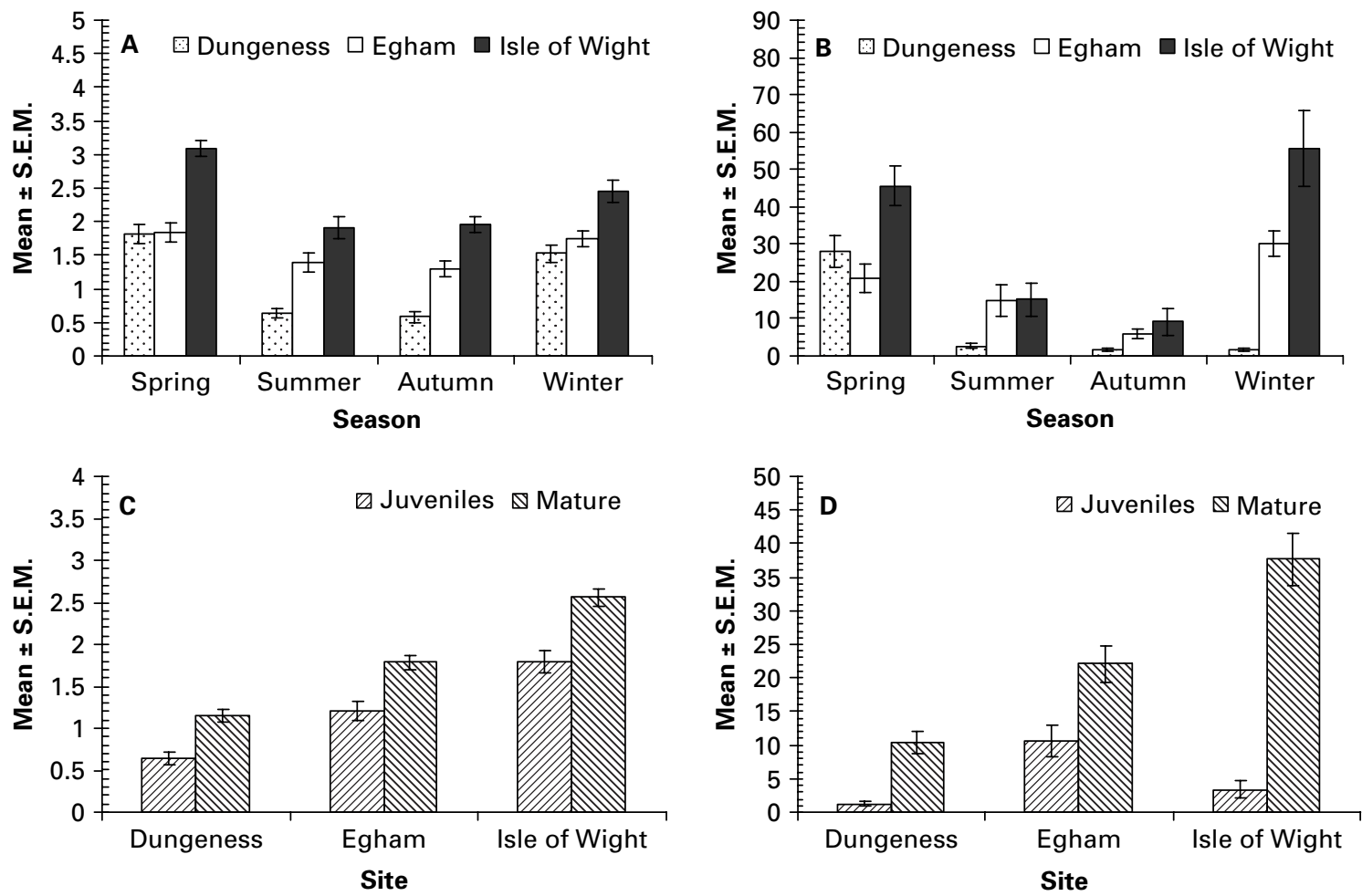

Fig. 5. Seasonal (A and $\mathrm{B})$ and age related $(\mathrm{C}$ and $\mathrm{D})$ variation in species richness $(\mathrm{A}$ and $\mathrm{C})$ and abundance of Heligmosomoides polygyrus (B and D) in three sites in SE England. For full details of methodology and statistical analysis see (Abu-Madi et al. 1998, 2000).

\section{Helminth communities in wood mice in southern England}

In the UK, one data-set on which we have published is also based on 3 sites, all examined in each of the four seasons in a single year and with a total sample of just under 400 animals. Here again we saw the highly predictable effects of season on mean species richness in all 3 sites. There were important differences between the sites, thus species richness was highest on the Isle of Wight, intermediate at Egham and lowest at Dungeness; Fig. 5A shows that the seasonal pattern was reflected almost identically in each of these three sites. The summer and autumnal dips were clearly apparent in all, with a rebound to higher levels for the winter and spring.

As is usual in the UK, H. polygyrus was the most prevalent species, and the seasonal pattern was also evident in this species (Fig. 5B), except that at Dungeness worm burdens remained low in the winter period and did not pick up until the spring. There were clear age-dependent increases in both species richness (Fig. 5C) and abundance of H. polygyrus (Fig. 5D).

\section{Core and satellite species}

From these studies, and the work of others (See Hanski, 1982 and Esch et al. 1990, for discussions of the concept of core and satellite species; Kisielewska 1970c; Montgomery and Montgomery, 1988; Haukisalmi and Henttonen, 2000), the picture that has developed is one of an underlying predictability provided by the core species, which are generally host specific in their definitive rodent hosts - the Heligmosomatidae (H. mixtum in bank voles in Poland, and $H$. polygyrus in woodmice in the UK) and some cestodes $(C$. henttoneni in bank voles in Poland). However, this is not universal. In spiny mice in Egypt, the dominant species Protospirura muricola is not specific to Acomys spp., although in the region Acomys dimidiatus is probably its most important host.

Occasionally we see rising/falling trends across years. A good example of that is Aspiculuris tetraptera in bank voles in Poland, which seems to have been increasing in abundance for the last decade, while Syphacia petrusewiczi has been declining (Bajer, Sinski et al. unpublished data).

Species that show great variation in number between individual hosts cause enormous problems in analysis. We have recovered over 9000 Syphacia petrusewiczi from a single bank vole. S. petrusewiczi, being a contact transmitting species, shows a good relationship with host density (Kisielewska, $1970 a$; Montgomery and Montgomery, 1988; Haukisalmi and Henttonen, 1990; Arneberg, 2001). However, Mesocestoides lineatus and Cladotaenia globifera, 




Fig. 6. The presence of $H$. polygyrus in woodmice increases the likelihood of infection with Catenotaenia pusilla, in each of three sites that were studied in SE England. The figure shows the prevalence of $C$. pusilla ( $\pm 95 \%$ confidence levels, CL) in mice that were, and were not, infected with $H$. polygyrus, at each site. For further details of the methodology and statistical analysis see Behnke et al. (2005).

where again there can be hundreds of larvae in one animal, even when the overall prevalence is $1 \%$, are further examples of unpredictable sporadic infections. All we can say about these is that the older the animal the more likely it is to be infected, and that infections in voles probably depend largely on the local presence of the definitive and first intermediate hosts.

Finally, we have another list of sporadic or satellite species which always show low prevalence and low intensity. They are largely unpredictable, their presence also depending on whether their definitive hosts have ventured into the site (e.g. mustelids that harbour the adults of Taenia mustelae and T. martis in the case of bank voles in Poland).

\section{Does Heligmosomoides polygyrus predispose wood mice to infection with other species of helminths?}

We were interested to see whether any support could be derived from field data for heligmosomatids increasing the likelihood of infection or abundance of infection with other species, as we might expect to be the case from the laboratory experiments with H. bakeri.

After analysing the data from the three-site study in SE England, we showed that indeed there were two robust relationships. One was with Catenotaenia pusilla. The prevalence of this species was always higher among mice that also harboured $H$. polygyrus. The significance of this relationship was tested in a model that also included season, age and sex and therefore controlled for the possible confounding effects of these factors, and yet it turned out to be robust, not confounded by other factors and reproducible in all three sites (Fig. 6).
Initially we sought a correlation between the intensity of $H$. polygyrus and $C$. pusilla, but selecting only those animals that were infected with at least one worm of each species and using the raw data, i.e. the actual worm burdens. This produced a correlation that was on the borderline of significance $\left(r_{s}=0 \cdot 24\right.$, $n=68, P=0.054)$, but such an analysis did not take into account the possibility that both species of worms may have been aggregated together in some subsets of mice (i.e. in a particular age group, sex, season or site. See earlier section entitled 'types of interactions and sources of error') or that differences between subsets obscured an underlying relationship. Therefore, we controlled for possible confounding factors, by fitting the residuals of minimum sufficient models in GLIM and the correlation improved quite markedly $\left(r_{s}=0 \cdot 32, n=68, P=\right.$ 0.008; Behnke et al. 2005).

Even more robust was the finding that wood mice that carried more $H$. polygyrus for their particular subset, also carried more other species of helminths. Fig. 7 shows that when we controlled for all other quantified factors that may have generated correlated exposure by testing the correlation between the residuals of minimum sufficient GLM models of the abundance of $H$. polygyrus and species richness among mice that were infected with $H$. polygyrus and at least one other species of helminth, there was indeed a highly significant positive relationship.

Since we completed that analysis I have been looking for opportunities to test this finding on other independent data-sets, and recently I have been able to do so through collaborations with Catarina Eira and her colleagues in Portugal and Spain. Eira et al. (2006) recently published on a large dataset from wood mice, sampled across 4 seasons from 6 distinct habitats on the Portuguese coast. These mice were not infected with $C$. pusilla and the prevalence of other cestodes was too low to repeat exactly the same test as that described above. We were able to test the relationship between $H$. polygyrus and mean species richness with other helminths and again we found a significant positive relationship after controlling for all confounding factors that were quantified (in this case differences between 6 habitats, 4 seasons, three age classes and both sexes). These data will be published separately. So once again wood mice with high $H$. polygyrus infections for their particular subset were shown to be more likely infected with other species of helminths for their subset.

In yet another opportunity to test the relationship between $H$. polygyrus and species richness with other helminths I recently analysed data collected by John Lewis at Royal Holloway (University of London). Originally we had published on the helminths of wood mice sampled over a 4 year period (Behnke et al. 1999), but the data now available were for 


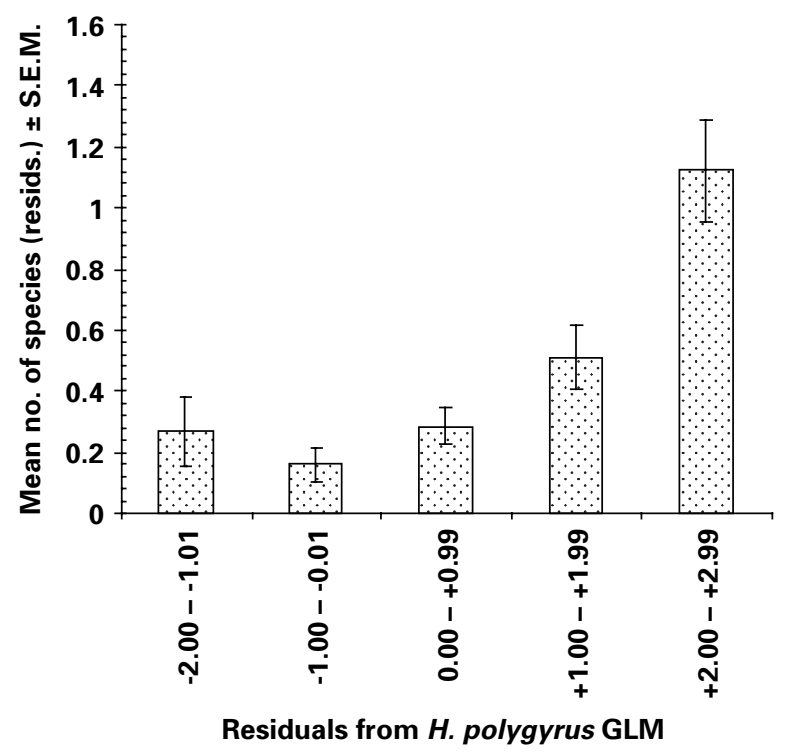

Fig. 7. Woodmice that carry more $H$. polygyrus for their subset, also have a higher species richness of other helminths for their subset $\left(r_{s}=0 \cdot 45, n=179, P<0 \cdot 001\right)$. See Behnke et al. (2005) for further details including full statistical approach and output.

9 years, one of the longest running UK datasets for helminths of wood mice. So this time the possible confounding factors were 9 annual datasets, 3 age classes and both sexes, but all from the same location and in the same season of the year, in late September. Again, when we controlled for all the quantified sources of variation of data we were able to demonstrate that wood mice heavily infected with $H$. polygyrus for their subset, also carried more species of other helminths for their subset (Behnke, Lewis et al. unpublished).

\section{CURRENT AIMS}

In the years ahead, we will look closely at possible relationships between helminths infecting bank voles in Poland, and also at relationships between the heligmosomatids and intestinal protozoan infections such as Cryptosporidium parvum and Giardia spp. which co-infect these animals and which we have already quantified (Bajer et al. 2004). Preliminary evidence suggests that synergistic co-occurrence between heligmosomatids and these intestinal protozoa is a feature of these systems (Bajer et al. 2004). Furthermore we were able to detect both cooccurrence and quantitative associations between Cryptosporidium parvum and Giardia spp. in bank voles (Myodes glareolus) and field voles (Microtus arvalis) in Poland (Bajer et al. 2002). Our analyses will be extended to murine communities in other ecosystems, notably the relatively species-poor helminth communities of spiny mice living in the arid terrain of the Sinai in Egypt, where we have already detected significant co-occurrence, although not quantitative associations, between intestinal protozoan infections (Cryptosporidium $c f$. parvum and Giardia sp.; Bajer et al. 2006).

\section{CONCLUSIONS}

Experimental data establish firmly that interactions exist between intestinal helminths of rodents, and that the strongest effects are mediated through the immune responses of the hosts, but detecting these relationships in naturally occurring wild rodent communities has been fraught with problems (Haukisalmi and Henttonen, 1993; Behnke et al. 2005) and published data do not support a major role for such interactions in structuring helminth communities in wild rodents (Kisielewska, $1970 a, b, c$; Montgomery and Montgomery, 1990; Haukisalmi and Henttonen, 1993; Poulin, 2001, Behnke et al. 2001). By understanding the role played by extrinsic and intrinsic factors in causing variation in parasite burdens, including species richness, it is possible to make some headway. Helminths of wild rodents show predictable patterns of seasonal, host agedependent and spatial variation in species richness and in the abundance of key core species such as the heligmosomatids. When these extrinsic and intrinsic sources of variation are controlled for, patterns of co-infection compatible with synergistic interactions can be demonstrated between intestinal helminths of wood mice, between gut protozoa and between haemoparasites in bank and field voles (Haukisalmi and Henttonen, 1993; Bajer et al. 2001, 2002). At least one of these, the positive relationship between $H$. polygyrus and the species richness of other helminths in wood mice, has been demonstrated in three totally independent data-sets, two drawn from the $\mathrm{UK}$ and one from Portugal.

The challenge now is to determine whether similar relationships exist for other heligmosomatids infecting other rodents in Europe where the helminth communities are generally depauperate and among host-parasite combinations in more distant parts of the world where helminth communities may be richer (Brouat et al. 2007 but see also Behnke et al. 2004). Nevertheless, whilst such relationships have already been shown to be repeatable, collectively they explain only a small percentage (usually less than $10 \%$ ) of the variance/deviance in abundance data. Although they may have a role to play in the more heavily infected animals, it is my view that other than in exceptional circumstances, quantitative interactions between species, as reflected in current worm burdens at sampling, are unlikely to play a major role in structuring helminth communities in wild rodents in Europe. Current worm burdens may well under-estimate the true consequences of co-infections, since current worm burdens need not necessarily reflect accurately the history of previous 
exposure and infection, including the possible polarisation of the immune system towards Th1 or Th2 responses and its consequences for different species (Graham, 2008). Interactions through the immune system over time, with one species preceding the next, may not be revealed with sufficient precision at a single sampling when animals are culled (e.g. hosts may have rejected earlier worm burdens and absence of worms may reflect immunity and cross-immunity between species as well as lack of exposure). To unravel the complexities involved and to fully evaluate the significance of time in such interactions, longitudinal studies are required with repeated sampling of the same marked animals, trapped frequently over long periods across seasons. Disappointingly, in comparison to the impressive studies on haemoparasites (Telfer et al. 2007a,b; including Telfer et al. in this issue) and viruses (Hazel et al. 2000), to the best of my knowledge, there are no comparable studies on helminth infections in wild rodents, an approach that must now be considered a priority for future researchers in this field.

\section{ACKNOWLEDGEMENTS}

The work described in this paper could not have been undertaken without the contribution, help and support of very many people over three decades, collaborators and students alike. My Polish colleagues, Edward Sinski and Anna Bajer are thanked in particular for their important contributions, comradeship and support, as are John Lewis from Royal Holloway and Marawan Abu-Madi from Qatar University. Chris Barnard, who sadly died earlier this year, provided inspiration and played an enormous role in our joint work over the years and is much missed. Phil Harris has helped me to organise expeditions abroad, to supervise the student contingents, to process endless tubes of guts and worms, and to prepare manuscripts. Francis Gilbert pioneered the statistical approaches that we have jointly introduced into the world of parasitology, and his watchful eye over our statistical analyses ever since is always much appreciated. Over the years, many colleagues from the UK and from aboard (most recently Catarina Eira, Jordi Torres and their co-workers), have sent me, and trusted me with, their raw unpublished data. Their generosity and trust are much appreciated. It is my immense pleasure to formally thank the many undergraduate students, too many to list here, who have contributed to our expeditions over the years in no short measure, often paid for their own fares and their living costs abroad, and who have provided much of the energy, enthusiasm and motivation for continuing with this sort of work, despite shoestring budgets and a current world dominated by the RAE. My own contributions to the work described here have been supported by travel grants from the University of Nottingham, the British Council and the Royal Society and by grants from the M.B. Grabowski Fund. Finally, I thank Phil Harris, Ian Duce, Joe Jackson, Derek Wakelin, John Lewis, Anna Bajer, Edward Siński, Catarina Eira and Andrew MacColl, all of whom read earlier version of this paper and provided constructive advice to help me refine the text. I also wish to thank two excellent referees who put much work into helping me improve yet further this final version of the manuscript.
REFERENCES

Abu-Madi, M. A., Behnke, J. M., Lewis, J. W. and Gilbert, F. S. (1998). Descriptive epidemiology of Heligmosomoides polygyrus in Apodemus sylvaticus from three contrasting habitats in south-east England. Fournal of Helminthology 72, 93-100.

Abu-Madi, M. A., Behnke, J. M., Lewis, J. W. and Gilbert, F. S. (2000). Seasonal and site specific variation in the component community structure of intestinal helminths in Apodemus sylvaticus from three contrasting habitats in south-east England. Fournal of Helminthology 74, 7-16.

Adams, D. B., Anderson, B. H. and Windon, R. G. (1989). Cross-immunity between Haemonchus contortus and Trichostrongylus colubriformis in sheep. International Fournal for Parasitology 19, 717-722.

Alghali, S. T. O., Hagan, P. and Robinson, M. (1985). Hymenolepis citelli (Cestoda) and Nematospiroides dubius (Nematoda): interspecific interaction in mice. Experimental Parasitology 60, 369-370.

Anderson, R. M. and May, R. M. (1982). Coevolution of hosts and parasites. Parasitology 85, 411-426.

Anthony, R. M., Urban, J. F., Jr., Alem, F., Hamed, H. A., Rozo, C. T., Boucher, J.-L., Rooijen, N. V. and Gause, W. C. (2006). Memory Th2 cells induce alternatively activated macrophages to mediate protection against nematode parasites. Nature, Medicine 12, 955-960.

Arneberg, P. (2001). An ecological law and its macroecological consequences as revealed by studies of relationships between host densities and parasite prevalence. Ecography 24, 352-358.

Artis, D. (2006). New weapons in the war on worms: identification of putative mechanisms of immune-mediated expulsion of gastrointestinal nematodes. International fournal for Parasitology 36, 723-733.

Artis, D., Wang, M. L., Keilbaugh, S. A., He, W., Brenes, M., Swain, G. P., Knight, P. A., Donaldson, D. D., Lazar, M. A., Miller, H. R. P., Schad, G. A., Scott, P. and Wu, G. D. (2004). $\operatorname{RELM} \beta /$ FIZZ2 is a goblet cell-specific immune-effector molecule in the gastrointestinal tract. Proceedings of the National Academy of Sciences, USA 101, 13596-13600.

Ashford, R. W. (1991). The human parasite fauna: towards an analysis and interpretation. Annals of Tropical Medicine and Parasitology 85, 189-198.

Ashford, R. W., Craig, P. S. and Oppenheimer, S. J. (1992). Polyparasitism on the Kenyan coast. 1. Prevalence and association between parasitic infections. Annals of Tropical Medicine and Parasitology 86, 671-679.

Bajer, A., Bednarska, M., Pawełczyk, A., Behnke, J. M., Gilbert, F. S. and Siński, E. (2002). Prevalence and abundance of Cryptosporidium parvum and Giardia spp. in wild rural rodents from the Mazury Lake District region of Poland. Parasitology 125, 21-34.

Bajer, A., Behnke, J. M., Bednarska, M., Kuliś, K. and Siński, E. (2004). Współwystępowanie Cryptosporidium parvum, Giardia spp. i helmintów w populacjach drobnych gryzoni. Wiadomosci Parazytologiczne 50, 307-315 (In Polish). 
Bajer, A., Behnke, J. M., Pawełczyk, A., Kulis, K., Sereda, M. J. and Siński, E. (2005). Medium-term temporal stability of the helminth component community structure in bank voles (Clethrionomys glareolus) from the Mazury Lake District region of Poland. Parasitology 130, 213-228.

Bajer, A., Harris, P. D., Behnke, J. M., Bednarska, M., Barnard, C. J., Sherif, N., Clifford, S., Gilbert, F. S., Siński, E. and Zalat, S. (2006). Local variation of haemoparasites and arthropod vectors, and intestinal protozoa in spiny mice (Acomys dimidiatus) from four montane wadis in the St. Katherine Protectorate, Sinai, Egypt. Fournal of Zoology 270, 9-24.

Bajer, A., Pawełczyk, A., Behnke, J. M., Gilbert, F. S. and Siński, E. (2001). Factors affecting the haemoparasitic component community structure in bank voles (Clethrionomys glareolus) from the Mazury lake district region of Poland. Parasitology 122, 43-54.

Barnard, C. J., Behnke, J. M., Bajer, A., Bray, D., Race, T., Frake, K., Osmond, J., Dinmore, J. and Siński, E. (2002). Local variation in endoparasite intensities of bank voles (Clethrionomys glaroelus) from ecologically similar sites: morphometric and endocrine correlates. Fournal of Helminthology 76, 103-112.

Begon, M., Townsend, C. R. and Harper, J. L. (2005). Ecology. Fourth Edition, Blackwell Publishing, Oxford.

Behnke, J. M. and Ali, N. M. H. (1984). Survival to patency of low level infections with Trichuris muris in mice concurrently infected with Nematospiroides dubius. Annals of Tropical Medicine and Parasitology 78, 509-517.

Behnke, J. M., Bajer, A., Siński, E. and Wakelin, D. (2000). Interactions involving rodent nematodes: experimental and field studies. Parasitology 122, S39-S49.

Behnke, J. M. and Barnard, C. J. (1990). Coevolution of parasites and hosts: host-parasite arms races and their consequences. . In Parasites: Immunity and Pathology. The Consequences of Parasitic Infection in Mammals (ed. Behnke, J. M.), Chapter 1, pp. 1-22. Taylor and Francis, London.

Behnke, J. M., Barnard, C. J., Bajer, A., Bray, D., Dinmore, J., Frake, K., Osmond, J., Race, T. and Siński, E. (2001). Variation in the helminth community structure in bank voles (Clethrionomys glareolus) from three comparable localities in the Mazury Lake District region of Poland. Parasitology 123, 401-414.

Behnke, J. M., Barnard, C. J. and Wakelin, D. (1992). Understanding chronic nematode infections: evolutionary considerations, current hypotheses and the way forward. International Fournal for Parasitology 22, 861-907.

Behnke, J. M., Bland, P. W. and Wakelin, D. (1977). Effect of the expulsion phase of Trichinella spiralis on Hymenolepis diminuta infection in mice. Parasitology 75, 79-88.

Behnke, J. M., Lewis, J. W., Mohd Zain, S. N. and Gilbert, F. S. (1999). Helminth infections in Apodemus sylvaticus in southern England: interactive effects of host age, sex and year on the prevalence and abundance of infections. Fournal of Helminthology 73, 31-44.
Behnke, J. M., Gilbert, F. S., Abu-Madi, M. A. and Lewis, J. W. (2005). Do the helminth parasites of wood mice interact? Fournal of Animal Ecology 74, 982-993.

Behnke, J. M., Harris, P. D., Bajer, A., Barnard, C. J., Sherif, N., Cliffe, L., Hurst, J., Lamb, M., Rhodes, A., James, M., Clifford, S., Gilbert, F. S. and Zalat, S. (2004). Variation in the helminth community structure in spiny mice (Acomys dimidiatus) from four montane wadis in the St. Katherine region of the Sinai Peninsula in Egypt. Parasitology 129, 379-398.

Behnke, J. M., Rose, R. and Little, J. (1994). Resistance of the hookworms Ancylostoma ceylanicum and Necator americanus to intestinal inflammatory responses induced by heterologous infection. International fournal for Parasitology 24, 91-101.

Behnke, J. M., Wakelin, D. and Wilson, M. M. (1978). Trichinella spiralis: delayed rejection in mice concurrently infected with Nematospiroides dubius. Experimental Parasitology 46, 121-130.

Biesmeijer, J. C., Roberts, S. P. M., Reemer, M., Ohlemüller, R., Edwards, M., Peeters, T., Schaffers, A. P., Potts, S. G., Kleukers, R., Thomas, C. D., Settele, J. and Kunin, W. E. (2006). Parallel declines in pollinators and insect-pollinated plants in Britain and the Netherlands. Science 313, 351-353.

Booth, M. and Bundy, D. A. P. (1992). Comparative prevalences of Ascaris lumbricoides, Trichuris trichiura, and hookworm infections and the prospects for control. Parasitology 105, 151-157.

Booth, M., Bundy, D. A., Albonico, M., Chwaya, H. M., Alawi, K. S. and Savioli, L. (1998). Associations among multiple geohelminth species infections in schoolchildren from Pemba Island. Parasitology 116, 85-93.

Bottomley, C., Isham, V. and Basanez, M.-G. (2005). Population biology of multispecies helminth infection: interspecific interactions and parasite distribution. Parasitology 131, 417-433.

Brouat, C., Kane, M., Diouf, M., Bâ, K., Sall-Dramé, R. and Duplantier, J. M. (2007). Host ecology and variation in helminth community structure in Mastomys rodents from Senegal. Parasitology 134, 437-450.

Bruce, R. G. and Wakelin, D. (1977). Immunological interactions between Trichinella spiralis and Trichuris muris in the intestine of the mouse. Parasitology $\mathbf{7 4}$, 163-173.

Bruna, C. D. and Xenia, B. (1976). Nippostrongylus brasiliensis in mice: reduction of worm burden and prolonged infection induced by the presence of Nematospiroides dubius. Fournal of Parasitology 62, 490-491.

Buck, A. A., Anderson, R. I. and MacRae, A. A. $(1978 a)$. Epidemiology of poly-parasitism. II. Types of combinations, relative frequency and associations of multiple infections. Tropenmedizin und Parasitologie 29, 137-144.

Buck, A. A., Anderson, R. I. and MacRae, A. A. (1978b). Epidemiology of poly-parasitism. IV. Combined effects on the state of health. Tropenmedizin und Parasitologie 29, 253-268.

Bundy, D. A. P. (1988). Population ecology of intestinal helminth infections in human communities. Philosophical Transactions of the Royal Society of London B321, 405-420. 
Bush, A. O., Heard, R. W. and Overstreet, R. M. (1993). Intermediate hosts as source communities. Canadian Fournal of Zoology 71, 1358-1363.

Bush, A. O. and Holmes, J. C. (1986). Intestinal parasites of lesser scaup duck: an interactive community. Canadian Fournal of Zoology 64, 142-152.

Castro, G. A., Olson, L. R. and Baker, R. D. (1967). Glucose malabsorption and intestinal histopathology in Trichinella spiralis infected guinea pigs. Fournal of Parasitology 53, 595-612.

Christensen, N. O., Nansen, P., Fagbeni, B. O. and Monrad, J. (1987). Heterologous antagonistic interactions between helminths and between helminths and protozoans in concurrent experimental infection of mammalian hosts. Parasitology Research 73, 387-410.

Christie, P. R., Wakelin, D. and Wilson, M. M. (1979). The effect of the expulsion phase of Trichinella spiralis on Hymenolepis diminuta infection in rats. Parasitology 78, 323-330.

Courtney, C. H. and Forrester, D. J. (1973). Interspecific interactions between Hymenolepis microstoma (Cestoda) and Heligmosomoides polygyrus (Nematoda) in mice. Fournal of Parasitology 59, 480-483.

Dehlawi, M. S., Wakelin, D. and Behnke, J. M. (1987). Suppression of mucosal mastocytosis by infection with the intestinal nematode Nematospiroides dubius. Parasite Immunology 9, 187-194.

Dawkins, R. and Krebs, J. R. (1979). Arms races between and within species. Proceedings of the Royal Society, London B205, 489-511.

Diez-Baňos, N., Cabaret, J. and Diez-Baňos, P. (1992). Interspecific interactions in naturally acquired nematode communities from sheep abomasum in relation to age of host and season in four areas of Leon (Spain). International Fournal for Parasitology 22, 327-334.

Dobson, A. P. (1985). The population dynamics of competition between parasites. Parasitology 91, 317-347.

Druilhe, P., Tall, A. and Sokhna, C. (2005). Worms can worsen malaria: towards a new means to roll back malaria? Trends in Parasitology 21, 359-362.

Eira, C., Torres, J., Vingada, J. and Miquel, J. (2006). Ecological aspects influencing the helminth community of the wood mouse Apodemus sylvaticus in Dunas de Mira, Portugal. Acta Parasitologica 51, 300-308.

Else, K. J. and Finkelman, F. D. (1999). Intestinal nematode parasites, cytokines and effector mechanisms. International Fournal for Parasitology 28, 1145-1158.

Elton, C. (1927). Animal Ecology. Sidgwick \& Jackson, London, republished in 2001 by The University of Chicago Press, Chicago.

Esch, G. W., Shostak, A. W., Marcogliese, D. J. and Goater, T. M. (1990). Patterns and processes in helminth parasite communities: an overview. In Parasite Communities: Patterns and Processes (ed. Esch, G. W., Bush, A. O. and Aho, J. M.), pp. 1-19. Chapman and Hall, London.

Ezeamama, A. E., Friedman, J. F., Olveda, R. M., Acosta, L. P., Kurtis, J. D., Mor, V. and
McGarvey, S. T. (2005). Functional significance of low-intensity polyparasite helminth infections in anaemia. Fournal of Infectious Diseases 192, 2160-2170.

Gause, W. C., Urban, J. F., Jr. and Stadecker, M. J. (2003). The immune response to parasitic helminths: insights from murine models. Trends in Immunology 24, 269-277.

Graham, A. L. (2002). When T-helper cells don't help: immunopathology during concomitant infections. The Quarterly Review of Biology 77, 409-434.

Graham, A. L. (2008). Ecological rules governing helminth-microparasite coinfection. Proceedings of the National Academy, USA 105, 566-570.

Graham, A. L., Cattadori, I. M., Lloyd-Smith, J. O., Ferrari, M. J. and Bjornstad, O. N. (2007).

Transmission consequences of coinfection: cytokines writ large? Trends in Parasitology 23, 284-291.

Guernier, V., Hochberg, M. E. and Guegan, J.-F. (2004). Ecology drives the worldwide distribution of human diseases. PLoS Biology 2, 740-746.

Hanski, I. (1982). Dynamics of regional distribution: the core and satellite species hypothesis. Oikos 38, 210-221.

Haukisalmi, V. and Henttonen, H. (1990). The impact of climatic factors and host density on the long-term population dynamics of vole helminths. Oecologia 83, 309-315.

Haukisalmi, V. and Henttonen, H. (1993). Coexistence in helminths of the bank vole Clethrionomys glareolus. I. Patterns of co-occurrence. Fournal of Animal Ecology 62, 221-229.

Haukisalmi, V. and Henttonen, H. (1998). Analysing interspecific associations in parasites: alternative methods and effects of sampling heterogeneity. Oecologia 116, 565-574.

Haukisalmi, V. and Henttonen, H. (2000). Variability of helminth assemblages and populations in the bank vole Clethrionomys glareolus. Polish Fournal of Ecology 48 (Suppl.), 219-231.

Hazel, S. M., Bennett, M., Chantrey, J., Bown, K., Cavanagh, R., Jones, T. R., Baxby, D. and Begon, $M$. (2000). A longitudinal study of an endemic disease in its wildlife reservoir: cowpox and wild rodents. Epidemiology and Infection 124, 551-562.

Holland, C. V., Asaolu, S. O., Crompton, D. W. T., Stoddart, R. C., MacDonald, R. and Torimiro, S. E. A. (1989). The epidemiology of Ascaris lumbricoides and other soil-transmitted helminths in primary school children from Ile-Ife, Nigeria. Parasitology 99, 275-285.

Holmes, J. C. (1961). Effects of concurrent infections on Hymenolepis diminuta (Cestoda) and Moniliformis dubius (Acanthocephala). 1. General effects and comparison with crowding. Fournal of Parasitology 47, 209-216.

Holmes, J. C. (1962a). Effects of concurrent infections on Hymenolepis diminuta (Cestoda) and Moniliformis dubius (Acanthocephala) 2. Effects on growth. Fournal of Parasitology 48, 87-96.

Holmes, J. C. (1962b). Effects of concurrent infections on Hymenolepis diminuta (Cestoda) and Moniliformis dubius (Acanthocephala) 2. Effects in hamsters. Fournal of Parasitology 48, 97-100. 
Holmes, J. C. (1973). Site selection by parasitic helminths: interspecific interactions, site segregation and their importance to the development of the helminth communities. Canadian Fournal of Zoology 51, 333-347.

Hopkins, C. A. (1980). Immunity and Hymenolepis diminuta. In Biology of the Tapeworm Hymenolpis diminuta (ed. Arai, H. A.), pp. 551-614. Academic Press, New York.

Howard, R. J., Christie, D., Wakelin, D., Wilson, M. M. and Behnke, J. M. (1978). The effect of concurrent infection with Trichinella spiralis on Hymenolepis microstoma in mice. Parasitology 77, 273-279.

Howard, S. C., Donnelly, C. A. and Chan, M.-S. (2001). Methods for estimation of associations between multiple species parasite infections. Parasitology 122, 233-251.

Howard, S. C., Donnelly, C. A., Kabatereine, N. B., Ratard, R. C. and Brooker, S. (2002). Spatial and intensity-dependent variations in associations between multiple species helminth infections. Acta Tropica 83, 141-149.

Hudson, P. J., Cattadori, I. M., Boag, B. and Dobson, A. P. (2006). Climate disruption and parasite-host dynamics: patterns and processes associated with warming and the frequency of extreme climatic events. Fournal of Helminthology 80, 175-182.

Janovy, J., Jr. (2002). Concurrent infections and the community ecology of helminth parasites. Fournal of Parasitology 88, 440-445.

Jenkins, D. C. (1975). The influence of Nematospiroides dubius on subsequent Nippostrongylus brasiliensis infections in mice. Parasitology 71, 349-355.

Jenkins, S. N. and Behnke, J. M. (1977). Impairment of primary expulsion of Trichuris muris in mice concurrently infected with Nematospiroides dubius. Parasitology 75, 71-78.

Keusch, G. T. and Migasena, P. (1982). Biological implications of polyparasitism. Reviews of Infectious Diseases 4, 880-882.

Keymer, A. E. (1982). Density-dependent mechanisms in the regulation of intestinal helminth populations. Parasitology 84, 573-587.

Kennedy, M. W. (1980). Immunologically mediated, non-specific interactions between the intestinal phases of Trichinella spiralis and Nippostrongylus brasiliensis in the mouse. Parasitology 80, 61-72.

Kisielewska, K. (1970a). Ecological organization of intestinal helminth groupings in Clethrionomys glareolus (Schreb.) (Rodentia). III. Structure of the helminth groupings in C. glareolus populations of various forest biocoenoses in Poland. Acta Parasitologica Polonica 18, 163-176.

Kisielewska, K. (1970b). Ecological organization of intestinal helminth groupings in Clethrionomys glareolus (Schreb.) (Rodentia). V. Some questions concerning helminth groupings in the host individuals. Acta Parasitologica Polonica 17, 197-208.

Kisielewska, K. $(1970 c)$. Ecological organization of intestinal helminth groupings in Clethrionomys glareolus (Schreb.) (Rodentia). 1. Structure and seasonal dynamics of helminth groupings in a host population in the Bialowieza National Park. Acta Parasitologica Polonica 18, 121-147.

Kvalsvig, J. D. (1988). The effects of parasitic infection on cognitive performance. Parasitology Today 4, 206-208.

Lello, J., Boag, B., Fenton, A., Stevenson, I. R. and Hudson, P. J. (2004). Competition and mutualism among the gut helminths of a mammalian host. Nature 428, 840-844.

Lotz, J. M. and Font, W. F. (1994). Excess positive associations in communities of intestinal helminths of bats: a refined null hypothesis and a test of the facilitation hypothesis. Fournal of Parasitology 80, 398-413.

Loukas, A. and Prociv, P. (2001). Immune responses in hookworm infections. Clincial and Microbiological Reviews 14, 689-703.

Maizels, R. M., Balic, A., Gomez-Escobar, N., Nair, M., Taylor, M. D. and Allen, J. E. (2004). Helminth parasites - masters of regulation. Immunological Reviews 201, 89-116.

Mercer, J. G., Mitchell, P. I., Moar, K. M., Bissett, A., Geissler, S., Bruce, K. and Chappell, L. H. (2000). Anorexia in rats infected with the nematode, Nippostrongylus brasiliensis: experimental manipulations. Parasitology 120, 641-647.

Mimori, T., Nawa, Y., Korenaga, M. and Tada, I. (1983). Nippostrongylus brasiliensis and Strongyloides ratti: concurrent infection in normal and immunized rats. Australian Fournal of Experimental Biology and Medical Science 61, 435-437.

Montgomery, S. S. J. and Montgomery, W. I. (1988). Cyclic and non-cyclic dynamics in populations of the helminth parasites of wood mice Apodemus sylvaticus. Fournal of Helminthology 62, 78-90.

Montgomery, S. S. J. and Montgomery, W. I. (1990). Structure, stability and species interactions in helminth communities of wood mice Apodemus sylvaticus. International Fournal for Parasitology 20, 225-242.

Moqbel, R. and Wakelin, D. (1979). Trichinella spiralis and Strongyloides ratti: immune interaction in adult rats. Experimental Parasitology 47, 65-72.

Murphy, K. M., Travers, P. and Walport, M. (2008). Faneway's Immunobiology (7th Edition). Garland Science Publications, London.

Nacher, M. (2002). Worms and malaria: noisy nuisances and silent benefits. Parasite Immunology 24, 391-393.

Nair, M. G., Guild, K. J. and Artis, D. (2006). Novel effector molecules in the type 2 inflammation: lessons drawn from helminth infection and allergy. Fournal of Immunology 177, 1393-1399.

Nawa, Y., Mimori, T., Korenaga, M. and Tada, I. (1982). Stage-specific cross-resistance between Nippostrongylus brasiliensis and Strongyloides ratti (Nematoda) in rats. Fournal of Parasitology 68 , 804-808.

Nilssen, A. C., Haugerud, R. E. and Folstad, I. (1998). No interspecific covariation in intensities of macroparasites of reindeer, Rangifer tarandus (L.). Parasitology 117, 273-281.

Nilsson, L. A. (1998). Deep flowers for long tongues. Trends in Ecology and Evolution 13, 259-260. 
Pedersen, A. B. and Fenton, A. (2006). Emphasizing the ecology in parasite community ecology. Trends in Ecology and Evolution 22, 133-139.

Pemberton, A. D., Knight, P. A., Gamble, J., Colledge, W. H., Lee, J.-K., Pierce, M. and Miller, H. R. P. (2004). Innate BALB/c enteric epithelial responses to Trichinella spiralis: inducible expression of a novel goblet cell lectin, Intelectin-2, and its natural deletion in C57BL/10 mice. Fournal of Immunology 173, 1894-1901.

Petney, T. N. and Andrews, R. H. (1998). Multiparasite communities in animals and humans: frequency, structure and pathogenic significance. International Fournal for Parasitology 28, 377-393.

Poulin, R. (1998). Evolutionary Ecology of Parasites. From Individuals to Communities. Chapman and Hall, London.

Poulin, R. (2001). Interactions between species and the structure of helminth communities. Parasitology 122, S3-S11.

Poulin, R. (1997). Species richness of parasite assemblages: evolution and patterns. Annual Reviews in Ecology and Systematics 28, 341-358.

Poulin, R. (2004). Macroecological patterns of species richness in parasite assemblages. Basic and Applied Ecology 5, 423-434.

Price, P. W. (1980). Evolutionary Biology of Parasites. Princeton University Press, Princeton, New Jersey.

Read, C. P. (1951). The crowding effect in tapeworm infections. Fournal of Parasitology 37, 174-178.

Roberts, L. S. (2000). The crowding effect revisited. Fournal of Parasitology 86, 209-211.

Rohde, K. (1991). Intra- and interspecific interactions in low density populations in resource-rich habitats. Oikos 60, 91-104.

Rzepecka, J., Lucius, R., Doligalska, M., Beck, S., Rausch, S. and Hartmann, S. (2006). Screening for immunomodulatory proteins of the intestinal parasitic nematode Heligmosomoides polygyrus. Parasite Immunology 28, 463-472.
Schad, G. A. (1963). Niche diversification in a parasitic species flock. Nature, London 198, 404-406.

Silver, B. B., Dick, T. A. and Welch, H. E. (1980). Concurrent infections of Hymenolepis diminuta and Trichinella spiralis in the rat intestine. Fournal of Parasitology 66, 786-791.

Stadler, B. and Dixon, A. F. G. (2005). Ecology and evolution of aphid-ant interactions. Annual Reviews of Ecology and Systematics 36, 345-372.

Telfer, S., Begon, M., Bennett, M., Bown, K. J., Burthe, S., Lambin, X., Telford, G. and Birtles, R. (2007a). Contrasting dynamics of Bartonella spp. in cyclic field vole populations: the impact of vector and host dynamics. Parasitology 134, 413-425.

Telfer, S., Clough, H. E., Birtles, R. J., Bennet, M., Carslake, D., Helyar, S. and Begon, M. (2007b). Ecological differences and coexistence in a guild of microparasites: Bartonella in wild rodents. Ecology 88, 1841-1849.

Tchuem Tchuenté, L.-A., Behnke, J. M., Gilbert, F. S., Southgate, V. R. and Vercruysse, J. (2003). Polyparasitism with Schistosoma haematobium and soil-transmitted helminth infections among school children in Loum, Cameroon. Tropical Medicine and International Health 8, 975-986.

Tokeshi, M. (1999). Species Coexistence : Ecological and Evolutionary Perspectives. Blackwell Science, Oxford.

Warren, M. and Wigglesworth, T. (2007). Large Blue. DEFRA factsheet from www.butterfly-conservation. org/conservation/defrafactsheets/butterflies.

Wilson, M. S., Taylor, M. D., Balic, A., Finney, C. A., Lamb, J. R. and Maizels, R. M. (2005). Suppression of allergic airway inflammation by helminth-induced regulatory T cells. Fournal of Experimental Medicine 202, 1199-1212.

Wootton, T. J. (1994). The nature and consequences of indirect effects in ecological communities. Annual Reviews of Ecology and Systematics 25, 443-466. 